\title{
Commentary
}

\section{Trees maintain a similar conductance per leaf area through integrated responses in growth, allocation, architecture and anatomy}

\author{
Frank Sterck ${ }^{1}$ and Roman Zweifel ${ }^{2,3}$
}

\begin{abstract}
${ }^{1}$ Forest Ecology and Management Group, Wageningen University, Droevendaalsesteeg 3, 6708 PB Wageningen, The Netherlands; ${ }^{2}$ Forest Dynamics, Swiss Federal Institute for Forest, Snow and Landscape Research (WSL), Zürcherstrasse 111, 8903 Birmensdorf, Switzerland; ${ }^{3}$ Corresponding author (roman.zweifel@wsl.ch)
\end{abstract}

Received August 23, 2016; accepted September 23, 2016; published online October 15, 2016; handling Editor Danielle Way

Trees look like solid and static creations, but during their long life they are continuously in action and fulfill many functions that influence their architecture, growth and reproduction. Key functions include the acquisition, transport and use of different resources (carbon, water, nutrients) and maintenance of a mechanically stable structure. The functions require coordination over the entire tree body, as failure at one location may result in tree death. Moreover, this coordination must be maintained while trees grow from small seedlings to big canopy trees, which may take centuries. Over this time span, forest trees gradually move their crown from relatively cool, moist and shaded conditions ( $\sim 1-3 \%$ relative to open sky light levels) to exposed conditions with higher day temperatures, drier air and greater exposure to wind (Chapin et al. 2004). An intriguing question is how trees develop and organize their tissues and organs during their life such that they maximize their carbon gain and ultimately reproductive output.

In their study in this issue of Tree Physiology, Petit et al. (2016) explore this question by studying branches of standard length $(\sim 80 \mathrm{~cm})$ of slow- and fast-growing Fraxinus trees in Italy. Branches represent small models of entire trees, since they also consist of leaves (for photosynthesis and transpiration), xylem (for water and nutrient transport), phloem (for sugar transport), buds (for shoot elongation and thus leaf production) and a cambium (for stem thickness growth, i.e., xylem and phloem production), but are much easier to sample than large trees. Moreover, in earlier work, Petit and Anfodillo (2009) showed that branches about 1-2 m from the apex represent an important hydraulic bottleneck in the water transport pathway of trees. This is mainly due to the tapering of xylem conduits, which become very narrow, resulting in a high resistance for water flow close to the apex (Mencuccini et al. 2007). In those branches, leaves (and petioles) add another hydraulic bottleneck in trees (Sack and Holbrook 2006). Consequently, branches represent an ideal model system for addressing questions regarding tissue and structural allocation to maintain effective carbon and water economies (Zhang et al. 2016), as explored in this study.

In their study, Petit et al. (2016) show that slow- and fastgrowing trees maintained similar hydraulic functionality (i.e., the water conductivity per distal unit leaf area) by their differential responses in allocation, architecture, anatomy and hydraulics. Such similar hydraulic functionality has also been reported for trees on soils differing in fertility (Whitehead et al. 1984) or under different water conditions (Addington et al. 2006), and for broad ranges of species (Meinzer 2003), but Petit et al. (2016) unravel this convergence in functionality in much more detail. They show that slow-growing trees allocated more biomass to their leaves and less to their xylem than fast-growing trees. These trees did so by producing shorter apical shoots with more leaves per shoot length than fast-growing trees. Slow-growing trees produced narrower annual rings with fewer but, remarkably, wider vessels in their branches than fastgrowing trees. As conduit conductivity increases with conduit diameter to the fourth power (according to the HagenPoiseuille equation), these larger vessels compensated for the hydraulic loss imposed by the smaller xylem area. Ultimately, these wider vessels did not increase cavitation vulnerability under water stress (i.e., lower water potentials), which implies that the production of wider vessels does not affect the drought 
tolerance of those branches. Such a trade-off between vessel size and cavitation vulnerability has been assumed in the literature (Cochard and Tyree, 1990), but more recent studies find little evidence for a trade-off between vessel size and cavitation vulnerability within species (Fichot et al. 2010, Sterck et al. 2012), suggesting that trees can control their conduit size independently — at least to some extent-from cavitation vulnerability. Overall, the slow-growing trees maintain hydraulic functionality that is similar to the fast-growing trees, but at lower costs of carbon investment.

In their discussion, Petit et al. (2016) hypothesize that such subtle responses associated with fast- versus slow-growing trees may be universal for trees under increasingly dry conditions. A recent study on fast-growing sun-exposed branches versus slow-growing shaded branches in a temperate, deciduous, broad-leaf forest (Zhang et al. 2016) also showed that trees control growth, architecture, allocation and anatomy to maintain hydraulic conductance per leaf area. Possibly, the same key mechanisms apply to different forms of stress: not only drought but also shade. Yet, Petit et al. (2016) suggest that the observed response will lead to a higher vulnerability of branches at greater height in a tree. This could explain crown dieback during extremely dry years (Brouwers et al. 2013), as well as the higher susceptibility to drought-induced death in tall, dominant trees (Laurance et al. 2000, Doughty et al. 2015). These observations suggests that there are limits to acclimation responses to water or light stress. At the same time, the observation of crown dieback confirm that branches are important bottlenecks in both the water and carbon economy of trees, and that they respond at least partially autonomously (Lacointe et al. 2004). This means that the separation of hydraulic bottlenecks in branches and in the stem could create a relevant and useful framework for studying hydraulics at the entire tree level.

We try to capture these results in a generic conceptual framework, following the hypothetical model for fast- and slowgrowing trees presented in the introduction of Petit et al. (2016), which we try to visualize in Figure 1. This model represents a single functional ring (the youngest one) in a fastgrowing tree and two functional rings (the youngest one, and the one of the previous year) in slow-growing tree. For the fastgrowing tree, the hydraulic pathway is determined by a series of resistances (length/(ring area $\times$ specific conductivity)), from stem, to branch twigs to leaves. The stem may act as a bottleneck, particularly when the tree becomes tall, the pathway increases in length and the gravitational pull downwards increases. The twigs and leaves act as bottlenecks because they have a low specific conductivity, mainly owing to their narrow conduits. For the slow-growing tree, a qualitatively equal series of resistances is observed in the outer ring, but the smaller ring area implies a higher resistance. However, the slowgrowing tree may compensate for this, not only by wider

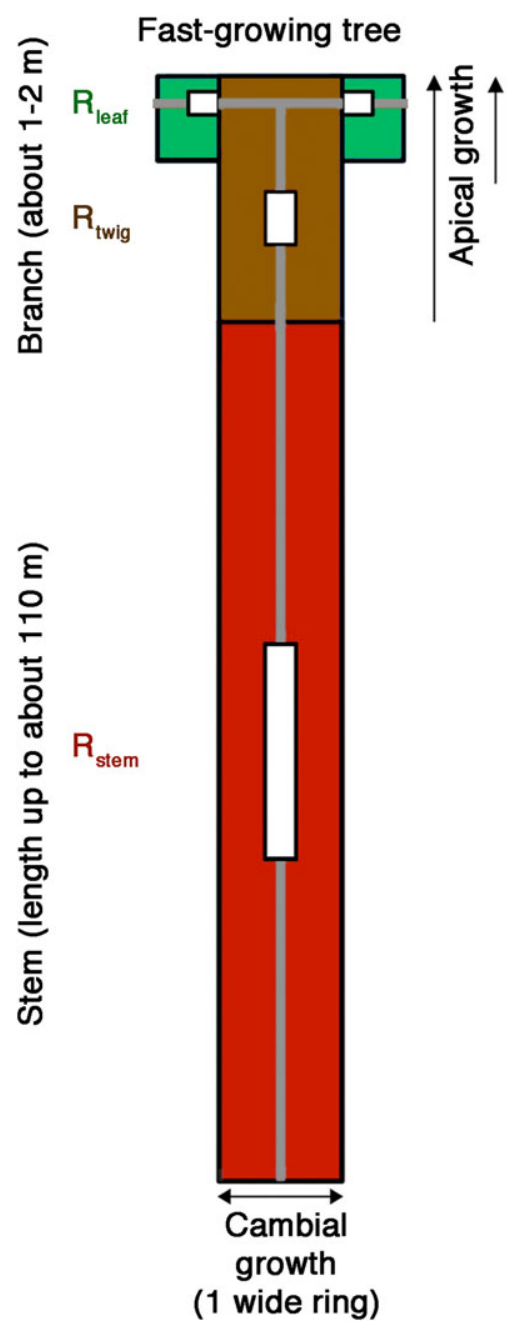

Slow-growing tree

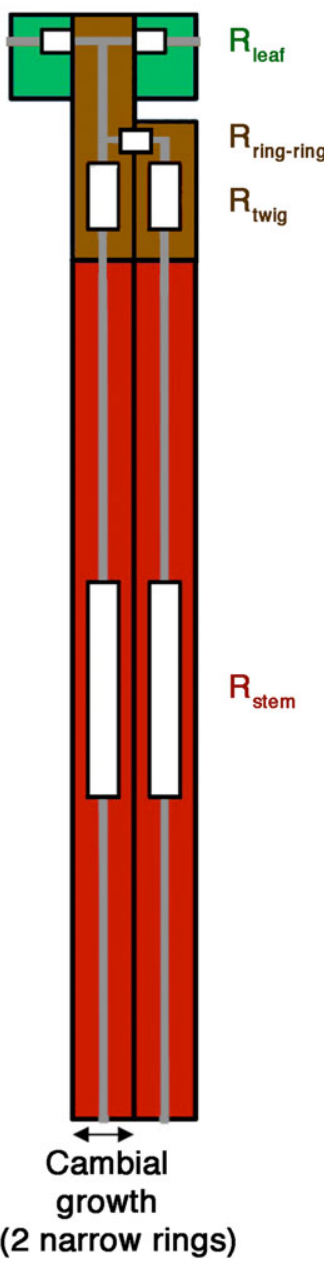

Figure 1. Conceptual graph identifying the key aboveground hydraulic bottlenecks to be considered in eco-physiological tree studies. Hydraulic architectures can be represented as an electric circuit, i.e., as a network of resistances (for clarity the resistances are indicated by $R$ ). The path-length effect is included in the stem resistance $\left(R_{\text {stem }}\right)$, and can thus capture differences between shoots on large and small trees, or shoots at the bottom and top of a tree crown. With increasing stem length, up to $\sim 110 \mathrm{~m}$ in for example redwoods on the USA westcoastal area (Koch et al. 2004), gravitational forces on upward water transport increase. Path-lengths are relatively constant for the branch consisting of 1-2 $m$ twigs (in brown, with resistance $R_{\text {twig }}$ ) and leaves (in green, with resistance $R_{\text {leaf }}$ ), but their specific conductance is much lower owing to the narrow tapering of their conduits. In the fast-growing tree (left), the outer growth ring is shown as the only one, since this represents the most extreme case of few rings that account for the water transport. In the slow-growing tree (right), growth rings are smaller, but one older ring also contributes to water transport (in reality there may be more functional rings, of course). Slow-growing trees thus compensate for the small individual ring area at low cost, since they are able to reuse the older structure for the current water supply. In a tree with compartmentalized xylem, or with more than one functional ring (as shown here), a further resistance from one ring to another is added $\left(R_{\text {ring-ring }}\right)$. These responses show how reduced apical shoot length growth, reduced cambial growth and maintenance of multiple functional rings allow slow-growing trees to maintain similar conductance per unit leaf area, comparable to those of fast-growing trees. The observed increase in conduit size, which also contributes to the conductivity in slow-growing trees, is not visualized here. 
conduits (Petit et al. 2016) but also by maintaining more functional xylem rings thus enlarging the total conductive crosssectional area. In our visualization of Figure 1, only a previous year ring was added to the current year ring for a slow-growing tree (Figure 1), but in reality more rings may be maintained (Sterck et al. 2008). In addition, another resistance is added to account for the radial transport from one ring to another. Of course, more realism can be created by adding more rings in this simple concept, as also implied by the results of Petit et al. (2016). Here, we used the concept to visualize the role of branches in the water economy of an entire tree: slow-growing trees can maintain a similar hydraulic functionality to fastgrowing trees, but at lower costs of carbon investment. In addition, this concept can be used for evaluating the water and carbon economy at the branch and entire tree level. In line with Petit et al. (2016), we call for studies on trees that quantify responses in anatomy, allocation, architecture and physiology to test the uniformity of their ideas on the coordination of water and carbon economies, particularly for branches on trees of different size (and age), branches at different heights in trees and for trees exposed to different environmental stresses. Such studies will allow us to better understand how trees coordinate their development during their life from seedling to canopy tree in different environments from the underlying mechanisms.

\section{References}

Addington RN, Donovan LA, Mitchell R, Pecot SD, Jack SB, Hacke UG, Sperry JS, Oren R (2006) Adjustments in hydraulic architecture of Pinus palustris maintain similar stomatal conductance in xeric and mesic habitats. Plant Cell Environ 29:535-545.

Brouwers N, Matusick G, Ruthrof K, Lyons T, Hardy G (2013) Landscape-scale assessment of tree crown dieback following extreme drought and heat in a Mediterranean eucalypt forest ecosystem. Landscape Ecol 28:69-80.

Chapin FS III, Matson PA, Mooney HA (2004) Principles of terrestrial ecosystem ecology. Springer-Verlag, New York.
Cochard H, Tyree MT (1990) Xylem dysfunction in Quercus: vessel sizes, tyloses, cavitation and seasonal changes in embolism. Tree Physiol 6:393-407.

Doughty CE, Metcalfe DB, Girardin CAJ et al. (2015) Drought impact on forest carbon dynamics and fluxes in Amazonia. Nature 519:78-82.

Fichot R, Barigah TS, Chamaillard S, Le Thiec D, Laurans F, Cochard H, Brignolas F (2010) Common trade-offs between xylem resistance to cavitation and other physiological traits do not hold among unrelated Populus deltoides Populus nigra hybrids. Plant Cell Environ 33:1553-1568.

Koch GW, Sillett SC, Jennings GM, Davis SD (2004) The limits to tree height. Nature 428:851-854.

Lacointe A, Deleens E, Ameglio T, Saint-Joanis B, Lelarge C, Vandame M, Song GC, Daudet FA (2004) Testing the branch autonomy theory: a ${ }^{13} \mathrm{C} /{ }^{14} \mathrm{C}$ double-labelling experiment on differentially shaded branches. Plant Cell Environ 27:1159-1168.

Laurance WF, Delamonica P, Laurance SG, Vasconcelos HL, Lovejoy TE (2000) Conservation: rainforest fragmentation kills big trees. Nature 404:836-836.

Meinzer F (2003) Functional convergence in plant responses to environment. 2003. Oecologia 134:1-11.

Mencuccini M, Holtta T, Petit G, Magnani F (2007) Sanio's laws revisited. Size-dependent changes in the xylem architecture of trees. Ecol Lett 10:1084-1093.

Petit G, Anfodillo T (2009) Plant physiology in theory and practice: an analysis of the WBE model for vascular plants. J Theor Biol 259:1-4.

Petit G, Savi T, Consolini M, Anfodillo T, Nardini A (2016) Interplay of growth rate and xylem plasticity for optimal coordination of carbon and hydraulic economies in Fraxinus ornus trees. Tree Physiol 1-10. doi: 10.1093/treephys/tpw069.

Sack L, Holbrook NM (2006) Leaf hydraulics. Ann Rev Plant Biol 57: 361-381.

Sterck FJ, Zweifel R, Sass-Klaassen U, Chowdhury Q (2008) Persisting soil drought reduces leaf specific conductivity in Scots pine (Pinus sylvestris) and pubescent oak (Quercus pubescens). Tree Physiol 28:529-536.

Sterck FJ, Martinez-Villalta J, Mencuccini M et al. (2012) Understanding trait interactions and their impacts on growth in Scots pine branches across Europe. Funct Ecol 26:541-549.

Whitehead D, Jarvis PG, Waring RH (1984) Stomatal conductance, transpiration, and resistance to water uptake in a Pinus sylvestris spacing experiment. Can J For Res 14:692-700.

Zhang L, Copini P, Weemstra M, Sterck F (2016) Functional ratios among leaf, xylem and phloem areas in branches change with shade tolerance, but not with local light conditions, across temperate tree species. New Phytol 209:1566-1575. 